\title{
Youth Housing Conditions in Tehran: Profiles and Challenges
}

\author{
Mohammad Taghi Sheykhi \\ Department of Social Science, Al-Zahra University, Tehran, Iran \\ Telephone: 009821-22859416, E-mail: mtshykhi@yahoo.com
}

KEYWORDS Youths; migration; squatters; housing shortage; urban planning

\begin{abstract}
As a specialist subject, sociology of housing seeks sociological explanations for a range of housing phenomena including patterns of housing and provision, patterns of inhabitation, household structures and the like. It also contributes much to housing management, urban sociology, policy studies and other related disciplines. The paper examines how the housing conditions are, and how planned housing could be provided in the growing city of Tehran. Due to the substantial economic and social decline in many rural and urban regions of the country, there has been a severe pressure of migration to Tehran in the past 3 decades, and the process has created the acute shortage of housing in the city with special reference to the youth who are not well-settled, and are of low-income social classes. Though well-planned housing can create conditions which are hygienic and environmentally conductive for healthy growth of human civilization, yet, Iran has a long time to go, to reach its objectives and thereby meet the housing needs of millions of inhabitants. On the contrary, unfavourable housing can lead to unlawful and unhealthy environment. However, the paper will explore how urgent the need to create a healthy housing atmosphere is in Tehran, especially among the youth. In the meantime, urban housing in Tehran assumes greater importance because of the various complex problems prevailing in the city. Some of such problems can briefly be summed up as: poverty and migration, squatters, dearth of land, lack of finance, violation of building regulations and so on. However, the unplanned and chaotic residential areas, if unable to cope with the surplus population, they are likely to convert into unhealthy squatters. So, the youth in Iran must tolerate the double pressure of housing provision, as well as marriage which cannot take place in time, due to the horror and shortage of housing.
\end{abstract}

\section{INTRODUCTION}

Housing planning means dealing with people's accommodation needs. However, all other projects, programmes and schemes are only secondary to the youth. Thus, public participation assumes great importance in housing and urban planning. Housing, being very important component of urban development, it comprises over 60 percent of land use of a city. The present research is based an a survey conducted on the youth aged 18-29 of both sexes in Tehran in January 2005 by the author, he came to know that highest frequency of the respondents to have personal accommodation was 21.9 percent belonging to age-group 25 of married youth. Having personal accommodation is a part of Iranian culture, and if the youth cannot possess it, almost all their monthly income should be paid for as rent. Therefore, purchasing a flat is of prime and vital importance for the youth in Iran. But, the scenario is too complicated, and it takes years to solve it. It even impedes marriage to take place among the youth in their early $20 \mathrm{~s}$.

Address for Correspondence: Dr. Mohammad Taghi Sheykhi, Pasdaran, Golnabi Street, Nategh-E-Noori Street, Koche Damghani, No. 17, Apt. \# 4, Tehran19478, Iran,
The topics covered are: the importance of housing, housing problems in Iran with a focus on Tehran, housing profiles and challenges, slum housing / squatters, data evidence etc.

The importance of housing needs no emphasis; it is one of our primary needs of life (Rao, 2001: 7). The housing problems in Iran are related more to the socio-economic and demographic conditions of the country. It is currently the same in other developing countries too. That is to say, our urban housing is the result of these conditions. Among housing agencies, the public and private sectors have equal responsibility for providing quality housing.

Overall, quality-planned housing can create conditions which are hygienic and environmentally conductive for healthy growth of human civilization. On the contrary, unsuitable housing can lead to unlawful and unhealthy environment. Thus, there is need to create healthy housing atmosphere, whether permanent or temporary. What the youth are urgently in need of, is lowcost housing. In addition, urban housing assumes greater importance since various complex problems prevail in urban areas.

Poverty being a multi-dimensional problem, and a major challenge all over the globe, its solutions are country specific (Uberoi, 2003: 6). 
Therefore, an effective strategy for tackling the problems of environment, development and poverty is to begin with the economic conditions of the youth, their resources and productivity. Sustainable Development must also address the issue of eradication of poverty which is linked with the employment of the youth and other income-generating programmes.

In the present paper, we will see how the human settlement conditions in Iran, and specifically in Tehran, are deteriorating mainly as a result of low investment sectors like housing and social welfare ${ }^{(1)}$ for the youth. The environmental implications of urban development and other human habitations (slums) must be recognized - giving priority to the needs of urban youth in particular.

\section{Housing Poverty}

Housing is not only a necessity of life, but also affects all aspects of our existence. Housing provides privacy and security against intrusions, both physical and emotional. It is the principal locus of our personal and family lives ( $\mathrm{Ha}, 2004$ : 140).

While the terms "housing poverty", "housing need" and "housing requirements" are widely used, their meanings are often unclear. Today, a good deal of recent sociological work on poverty has concentrated on the idea of social exclusion. The proposition is that since the poor (here the youth) are excluded by their poverty from mainstream society, they in effect lose the benefits and privileges of their citizenship. That exclusion may not only be wrong in principle, but it also means that the poor (the youth) have no stake in society; thus one of the foundations of social order is thereby undermined (Turner et al., 2000: 274). Poverty is not simply low or inadequate income, but refers also to a lack of physical necessities and other assets (savings, resources etc.). Often, poverty is precipitated by a loss of assets. Poverty implies deprivation of human needs including housing that is not met. As such, measurements of poverty that are based solely on economic needs, have been criticized for their inability to portray well-being accurately. Measures that incorporate a broader range of indicators including non-economic dimensions, have been advanced as being conceptually more useful. Such an argument can apply to the youths' housing poverty as well.
However, housing needs have been defined in general terms as the extent to which the quantity and quality of the existing accommodation falls short of, that required to provide each household or person in the population irrespective of ability to pay, or not having specified minimum required standards (Needleman, 1965: 18).

The concept applies to features such as:

The basic problems of housing shortage, poor physical conditions, and overcrowding.

The suitability of the dwelling stock in terms of tenure, type, size, location and other qualitative aspects of the dwelling and neighbourhood environment.

The ability of households (specially the young ones) to gain access to suitable dwellings.

\section{Youth and Change}

Youth have been described as the "barometer of social change ". They are intimately affected by the changes of the world, and respond most effectively to them. However, the generational divide should not become a social divide. The new society must seek to prevent exclusion, integrate the young and the old, and the rich and the poor (Tiong, 2004). Young people need to deal with vulnerabilities, and establish themselves in a new social context. The new world provides new possibilities as well as threats, in promoting diversity, solidarity and sustainability. However, one of the challenges identified in front of the youth in the new era, is housing of the youth in countries like Iran with very young population structure. Iran's population like many other developing societies is actually young with the median age of 23.3 in 2004 (SCI, 2004).

Iran, in the past few decades has rapidly changed from a more traditional society into a modern society and from joint family system to nuclear family system in which the housing of the youth has become more acute and problematic. The paper reflects an analysis of the profile of youth in Tehran including the employment, education, and housing and as a whole, lifestyle. The paper explores the opportunities and challenges of such human capital in various dimensions.

\section{Literature Review}

Urbanization or the process in which people 
move to large cities from rural areas reflects the interaction between society and environment. Housing problem itself is assumed to be the result of such interaction and the ultimate incidence of which is on the youth.

As a result of population explosion, the urban areas in Iran are also exploding and the rapid urbanization is taking its toll in the country. Urbanization trends have been unprecedentedly increasing in Iran in the past two decades reaching 66 percent in 2003 (PRB, 2003). However, like other developing countries, Iran is also a victim of rapid increase in urban population as a result of very fast rise in its population - contributing to housing challenges extremely among the increasing young cohorts.

Cities have a range of features including the loss of primary relationships, weaker social control, a great division of labour, and currently increasing in-migration. These features are caused mainly by three basic factors - the numbers, density and heterogeneity of population (Wirth, 1938). All these factors are somehow or the other responsible for the housing conditions in Iran. In his perspective, Wirth was faithful to the principles of urban ecology in holding that fundamental features of urban environment produce the entire range of urban social behaviour - leading to social problems of housing among the youth.

Though according to the social mobility perspective, as proposed by Lipset and Bendix (1959), stability of modern industrial society is maintained, and therefore there will be open access to elite positions, yet controversies emerge and as a result housing problems appear among other urban issues.

Based on sociology of everyday life, and though much of sociology is preoccupied with the analysis of large-scale structures such as the family, the work institutions, or the state, yet an important branch of the discipline has been concerned with the analysis of the socio-cultural and economic arrangements of housing conditions of the newly-emerging and young households (Lefebvre, 1991). However, technological determinism believes that technology is responsible for the nature of social relations at work, individual job satisfaction, life and housing conditions (Turner, 2000: 341).

Sociological approach and social networks are very much concerned with social interactions and influence the economic ability of the individuals in the society. Economic sociology identifies the relationship between economic status of the individuals and their access to quality housing (Smelser et al., 1994). However, development of a sociological analysis of economic phenomena though was a central concern of classical sociologists such as Marx, Weber and Durkheim, yet the approach under the title of new economic sociology (NES) play a leading part in solving the youths' need / demand towards housing.

Demographic combination of cities which are mainly two features is that; cities include more youths compared with rural areas which have more elderly population; and that is because cities attract youths for leisure and employment purposes. But, they always do not attain their goals - they more often remain unhoused (Kazemi-e-Bidhendi and Hesamian., 1978: 56). Such young population structure will further escalate the housing conditions in Iran and in Tehran in particular. Statistical evidence indicates that during 1986 - 1996 the proportion of inmigrants to Tehran Province has been 30.6 percent; about one-third of all, as compared with other 25 provinces of the country (SCI, 1998: 18). Such a situation escalates housing conditions of the increasing youths in Tehran city.

Another perspective indicates that migration diverts the natural distribution of population by sex in various age groups, and as a result, different consequences/effects appear (Zanjani, 1991: 45). That means, the males would outweigh the females under the migration trends in search of jobs in cities; and that impairs the sex ratio in the cities which is not advisable either.

Due to the increasing trends of industrialization in the country in the past four decades particularly in Tehran, $33 \%$ of the total industrialization occurred in this city, and because of the rise in oil revenues since early 1970s, and due to increasing changes in rural areas, waves of exploding migrations to Iranian cities in particular to Tehran thence started (Sadigh-eOreie, 1995: 73). Such a scenario contributed to change in life patterns, change in urban way of life, change in expectations and family lifeleading to housing conditions of the youth with special reference to Tehran.

\footnotetext{
Aims

The important focus of the research is the dissemination and promotion on a variety of
} 
housing issues which usually the youths in Iran / Tehran face. The study aims to identify some of the realities of housing in social, economic and cultural contexts. The paper will discuss the findings and draw conclusions based and the original data. The paper will pursue the objectives as to how housing for the youth and low-income inhabitants is continuing. Housing dilemma will follow the materials, theories and relevant literature pertaining to the issue. The research also aims to somehow determine the level of housing satisfaction experienced by the youth. The paper will assess how the pace of urbanization during the past decades affected the size and structure of cities in Iran, particularly in Tehran. The phenomenon has led to increasing housing needs mainly by the youth within the poorer classes.

\section{METHODOLOGY}

The research techniques used in the present project to find specific facts, and the operations required to yield the required social data, have been of a mixed-method strategy of investigation. While the main method of study in this research was administering questionnaires, the author used interview as per necessary. However, books and documents as major sources of evidence were used too, as primary source materials. In the theoretical section, the author has referred to various relevant theories, approaches, literature review etc. In completing the research, 400 questionnaires were filled in, and in that, related direct and indirect queries were posed, elicited and finally extracted, to produce a reliable and valid work.

\section{Theoretical and Conceptual Analyses}

The theory of housing classes was introduced by Rex and Moore (1967). Their argument is that the population can be grouped into distinct housing classes - the owners of the houses, the tenants and so forth. Though the theory was illustrated decades back, yet, it is more observable today since more social classes including the youth are seen in cities searching accommodation.

The problem of homelessness ${ }^{(3)}$ among the youth is also observable in many parts of the world as well as Iran. But, in Iran according to the national cultural norms and standards, inevitably many youths, yet live and stay with their families in their twenties or even beyond. Homelessness or the situation of having no home or permanent abode is a significant concept in the sociology of housing particularly among the youth. However, the phenomenon of "hidden homelessness" is also growing in many parts of the world even in developed countries (Jary, 1999: 290). Some writers have seen the growth of homelessness as a result of the under-supply of social housing, others as a result of changing conditions of life for young people including high youth unemployment rates and changing patterns of family life. Both of these types of explanations have evidence to support them.

Moving away from traditional Marxian approaches which identify two main classes in terms of their relationship to the means of production, Rex and Moore adopt a more flexible Weberian approach which identifies a variety of classes according to their "market situations", and consequently one such market is housing. Thus, they introduce the notion of housing classes (Richardson and Lambert, 1995: 73). In this scenario, an individual might occupy a powerful position in the labour market, but this does not necessarily reflect power and influence in the housing market, and as a result, the person may live in a low-quality neighbourhood such as many immigrants in the industrial cities.

Unemployment and urban deprivation prominently contribute to the emergence of various issues with special reference to the youth. Such civil disturbances are assumed to be the beginning of further problems. Economic marginality also contributes to housing problems, urban unrest, and even involvement in violent protest (Fogelson, 1971).

However, urbanization continues apace in the contemporary world, producing pressing health problems, and that has led to the fact that the most heavily populated cities in the world face acute problems of public health (McMichael, 1993: 267).

In a purely private housing market, housing is allocated entirely on the basis of ability to pay. Households and the youth in particular vary in the amount of money they can spend on housing. The best housing therefore goes to those who can afford it.

\section{Stages in the Life-ycle}

Through its life-cycle, the typical household 
Table 1: General housing needs associated with different stages of the life-cycle

\begin{tabular}{|c|c|}
\hline Stage in life - cycle & Housing needs / aspirations \\
\hline 1 Pre-child stage & Relatively cheap, central-city apartment \\
\hline 2 Child-bearning & Renting of single-family dwelling close to apartment zone \\
\hline 3 Child-rearing & Ownership of relatively new suburban home \\
\hline 4 Child-launching & Same areas as (3) or perhaps move to higher- status area \\
\hline 5 Post-child & Marked by residential stability \\
\hline 6 Later life & Institution / apartment / live with children \\
\hline
\end{tabular}

has a variety of space requirements. In Western cities the youth typically leave their parents' homes even before they enter their twenties, while in Iran it does not always happen so. They usually stay with their families / parents until they marry. While in many countries, particularly in Western Europe, according to the social housing programmes, housing is allocated on the basis of need rather than income, in Iran, such programmes are not there. In social housing method, government intervention can allow low-income households to live in very pleasant housings. However, the amount of social housing varies. It is very small in the United States, and limited to the very poorest, whereas in Scandinavian countries it constitutes a significant proportion of the total housing stock. It becomes a target for attack whenever there is a crisis in government finances (Short, 1997: 194) (Table 1).

\section{Profiles and Challenges}

The prevailing housing problems in Iran in general, and in Tehran in particular, could briefly be summed up and discussed as follows:

\section{Poverty and Migration}

All major problems in Iran are related to poverty and high growth rate of population in the past three decades, and housing is not an exception. Though recently there is an increasing emphasis on restricting the family size to control the growth rate of population, yet there is largescale unemployment in rural areas and smaller towns and cities. As a result, they (the youth) have to find alternative ways of employment to make a living. As there are limited employment opportunities in rural areas, they migrate to cities, and the entire scenario leads to concentration of population in a few selected cities including Tehran for employment. Similarly, as there are not infrastructures enough in the city, housing has become problematic in Tehran.

\section{Unhealthy Housing and Slums}

The rapid pace of urbanization in Iran has created unhealthy, semi-standard and nonstandard housing and in some locations even slums. They have become the most complicated problem in many cities in Iran including Tehran. The youth in such accommodations are highly prone to addiction, alcoholism, criminal behaviour, deviance, divorce, poverty, abnormal behaviour and the like. However, urban unhealthy housing is not a physical problem, yet, it is a physical manifestation of deeper socio-economic problems prevailing in the country. The migrants not only create unhealthy slums, but they also deteriorate the urban centres. It is impossible to solve this complex problem without preventive measures. It could be concluded that housing the urban poor youths is a major challenge of modern cities.

\section{Dearth of Land / Lack of Finance}

The dual problems of dearth of developed land for housing, and the unafforability to pay for, are two major problems of housing being faced by the youth, not only in Iran, but in many other developing countries with inflationary economies. While the general purchasing power of each person should be improved, finance also should be made available depending upon the repaying capacity of the individual. Lending of loans is not also easily available for the urban poor and the youth in general, but it is more available for housing institutions.

\section{Violation of Building Regulations}

Violation of building regulations is a sort of a menace in cities. These violations are normally seen in zoning, setbacks, building height, builtup area, unauthorised constructions etc. However, liberalised and specific building regulations without political relaxations would be extremely useful to curb these tendencies and create healthy housing environment. 


\section{Interpretation of Data}

In the empirical section, youths within the age groups 18-29 were surveyed (Table 2). Variables such as occupations, education, marriage, accommoda-tion ownership, tenancy and the like were among the key questions sought. They were the variables which directly and indirectly related with housing conditions of the youth-some as profiles and others as challenges.

So far as the income of our statistical population is concerned, the highest income in agegroup 29 i.e. (24.4\%) belonged to those youths whose monthly income was between US \$ 88 and 116 (Rials 750000-990000), and for higherincome groups, those aged 22 (18.2\%), reported their monthly income between US \$ 117 and 175 (Rials 1000000-1490000). Those in higher-income category of the samples belonged to age-group $27(21.3 \%)$, who reported their income more than US \$ 176 (Rials 1500000 and more) a month.

All such incomes place the youth in poverty and even under poverty line - not allowing them to have adequate housing. Under such income poverty conditions, larger numbers of our samples were graduated. Most of the youth surveyed $(77.3 \%)$ were unmarried, and only $(22.7 \%)$ reported to be married. The main reason for such a great difference is supposed to be the housing problem. Because of the complicated housing conditions and the dearth of rent/price, many youths prefer to remain unmarried as long as possible.

According to the Iranian culture, norms and values currently prevalent in the society, and under the present housing and employment conditions, yet, larger proportion of them economically depend on their families. In terms of data obtained, $46 \%$ of the respondents declared that they fully depended on their families. While $30.7 \%$ economically depended on their families to some extent, about $23 \%$ reported to be selfreliant. While among the female respondents, viz, out of $200,(61.5 \%)$ reported to depend on their families, among males, $30.5 \%$ reported to be dependent on their families.

One of the difficulties/challenges of the Iranian youth is that, in many cases, they should be in charge of some part of their family expenditures, and that cripple/disable the youth to pay for their own housing. In this research, $21 \%$ of our respondents declared that they were partially in charge of their family expenditures and $5.5 \%$ were entirely responsible for their family expenses. So far as the male respondents are concerned, $31 \%$ of them responded that they were partially in charge of their family expenditures, and $8.5 \%$ were totally so responsible. In case of female respondents, $11 \%$ declared that they were, to some extent responsible for their family expenditures, and $2.5 \%$ were entirely in charge of their family living costs.

In the survey conducted, the author came to know that almost a quarter of the respondents declared that they had not been in a position to travel at all during the past 12 months. The reason for which could be poor financial conditions and shortage of facilities.

Despite living in a large city like Tehran, more than $75 \%$ of the samples did not have any means of transportation. While this ratio was $66.5 \%$ for the males, it was $85 \%$ for the female respondents.

Table 2: Married youths by housing conditions

\begin{tabular}{|c|c|c|c|c|c|c|}
\hline \multirow[t]{2}{*}{ Age Groups } & \multicolumn{2}{|c|}{ Total } & \multicolumn{2}{|c|}{ Tenants } & \multicolumn{2}{|c|}{ Ownling Independent Housing } \\
\hline & No. & $(\%)$ & No. & $(\%)$ & No. & $(\%)$ \\
\hline All Ages / Conditions & 91 & $(100.00)$ & 59 & $(100.00)$ & 32 & $(100.00)$ \\
\hline 18 & 0 & $(0.00)$ & 0 & $(0.00)$ & 0 & $(0.00)$ \\
\hline 19 & 1 & $(1.10)$ & 0 & $(0.00)$ & 1 & $(3.13)$ \\
\hline 20 & 3 & $(3.30)$ & 3 & $(5.08)$ & 0 & $(0.00)$ \\
\hline 21 & 8 & $(8.79)$ & 4 & $(6.78)$ & 4 & $(12.50)$ \\
\hline 22 & 7 & $(7.69)$ & 5 & $(8.47)$ & 2 & $(6.25)$ \\
\hline 23 & 8 & $(8.79)$ & 6 & $(10.17)$ & 2 & $(6.25)$ \\
\hline 24 & 8 & $(8.79)$ & 7 & $(11.86)$ & 1 & (3.13) \\
\hline 25 & 19 & $(20.88)$ & 12 & $(20.34)$ & 7 & $(21.88)$ \\
\hline 26 & 4 & $(4.40)$ & 3 & $(5.08)$ & 1 & $(3.13)$ \\
\hline 27 & 16 & $(17.58)$ & 11 & (18.64) & 5 & (15.63) \\
\hline 28 & 9 & $(9.89)$ & 4 & $(6.78)$ & 5 & (15.63) \\
\hline 29 & 8 & $(8.79)$ & 4 & $(6.78)$ & 4 & $(12.50)$ \\
\hline
\end{tabular}

Source: Main Empirical Survey 2005. 
On the other hand, $12.3 \%$ of the unmarried and $18.7 \%$ of the married samples in the survey owned personal cars. It indicates that the married are more established/settled.

Out of the total youth who had housing, $24.2 \%$ were partially in charge of their family expenditures, and $16.5 \%$ were completely in charge of that. Similarly, $18.6 \%$ of those living in renting houses were partially, and $20.3 \%$ were totally in charge of their family expenditures. In case of the youth owning their housings, $34.4 \%$ were partially and $9.4 \%$ were completely in charge of their family expenditures.

Indeed, a high number of Iranian youths living in poverty have to live in unfit and poor-standard houses, and many of those homeless, compulsorily live with their parents. Generally speaking, poor socio-economic conditions in many cases and in different countries, delay employment, independent housing and forming new families of the youths (Hill, 1997: 167).

\section{CONCLUSION}

The purpose of the present paper is to examine and assess affordable and quality housing vis-àvis the youth in Tehran. Housing the poor will fail unless policy-makers address the underlying classes and the inequalities that persist in shaping social stratification. Quality housing as are of the primary needs of the youth, could eventually lead to healthy environment and social well-being. Therefore, an effective strategy to tackle the housing conditions of the youths is to improve their economic conditions; viz, a process which will affect all the aspects of existence. The problem of homelessness in an overt and covert manner affects even national cultural norms and standards, and that needs efficient management. However, unemployment significantly contributes to the emergence of various issues including the youth housing and a range of social problems. Similarly, under the conditions of the rise in oil revenues since 1970s, and consequently reconstruction in Tehran, large number of workers has migrated to this city. Such a perpetuating movement has culminated into complicated problems including housing for the youth, i. e. a scenario which needs further improvements.

\section{NOTES}

Social Welfare: The concept denotes that access to welfare services is a crucial component of citizenship. The function of applied sociology is not limited to mere study of social malfunctions and disorganization; rather, its primary motivation and interest lie in the reconstruction and welfare. That is, correction or remedy of disorganizing causes, factors, social rehabilitation and welfare of mal-adjusted and misfit individuals. It must be borne in mind that social welfare is a dynamic and progressive concept which contributes to overall wellbeing of the citizens regardless of their caste, creed, race and religion.

Housing Poverty: It is a state of housing deprivation in which the human needs are not met. In that, people or households are unable to pay and have access to accommodation of a specified minimum standard. The concept also includes housing shortage, poor physical conditions in terms of size, type, normative housing qualities, location, minimum floor space, lacking basic services and facilities such as running water, electricity and poorly-built structures.

Homelessness: It is a concept of housing exclusion based on a number of assumptions, and has a number of implications. That is more due to poverty and social marginality, in terms of (non) accommodation. Homelessness in its narrow sense refers to persons with no accommodation, roofless, people sleeping rough etc., and also people who find shelter through temporary accommodation in institutions. It also refers to people who are subject to substantially unacceptable housing conditions.

Housing Classes: Housing classes are independent of social classes. Although they are also a feature of social inequality since not all housing is equally desirable, in urban context, everybody wants housing, but not everyone has access to it, and hence there is competition and struggle between housing classes. However, housing classes are really a function of the social class structure.

\section{REFERENCES}

Dhaliwal, S. R., G. S. Sangha and P. K. Ralhan. 2000. Fundamentals of Environmental Science. New Delhi: Kalyani Publishers.

Enumeration of the Characteristics of Employment and Unemployment in Iran. 2004. Iran: Statistical Center of Iran (SCI).

Fogelson, R. M. 1971. Violence as Protest: A Study of Riots in Ghettos. New York, Doubleday.

$\mathrm{Ha}$, Seong-Kyu quoted in Environment and Urbanization, 2004, 15(1): 140

Hill, M. and K. Tisdall. 1997. Children and Society. New York: Addison Wesley Longman Inc.

Kazemi-e-Bidhendi, M. and S.Hesamian 1978. Concept of City 2, Urban and Regional Studies. Tehran: Urban and Regional Group Publishers.

Lefebvre, H. 1971. Critique of Everyday Life. London: Verso.

Lipset, S. M., and R. Bendix. 1959. Social Mobility in Industrial Society. Berkeley, University of California Press.

McMichael, A. J. 1993. Planetary Overload, Global Environmental Change and the Health of the Human Species. Cambridge: Cambridge University Press.

Needleman, L., 1965. The Economics of Housing, (p. 18), London: Staples Press.

Noorulahi, T. 1998. Internal Migration in Iran (1986 - 
1996), (P. 18), Tehran: Statistical Centre of Iran Publications.

Rao, M. P. 2001, Urban Planning: Theory and Practice, (p. 1\&7), New Delhi: CBS Publishers and Distributors.

Rex, J. and R. Moore. 1967. Race, Community and Conflict. London: Oxford University Press.

Richardson, J. and J. Lambert. 1985. The Sociology of Race. Ormskirk: Causeway.

Sadigh-e-Oreie, G. 1995. Youths' Social Problems. (p.

73), Mashhad, Iran: Jihad Daneshgahi Publications.

Short, J. R.. 1997. The Urban Order. (p. 194), Oxford: Blackwell Publishers.

Smesler, N. J., and R. Swedberg. 1994. Handbook of Economic Sociology. Princeton, NJ: Princeton University Press.

Tiong Tan, N. 2004. Strategies for the Development of
Human and Social Capital. Hong Kong Baptist University and Chinese YMCA of Hong Kong, Working with Youth in a Rapidly Changing World (P.E-8)

Turner, B. S., N. Abercrombie and S. Hill. 2000. The Penguin Dictionary of Sociology. (p. 274), London: Penguin Books.

Uberoi, N. K. 2003. Environmental Management. (P. 6), New Delhi: Excel Books.

Wirth, Louis. 1938. "Urbanism as a Way of Life." American Journal of Sociology, 44: 1-24.

World Population Data Sheet. 2003. Washington, DC: Population Reference Bureau.

Zanjani, H. 1991. Issues and Methods of Urban Planning: 1-Population. (p. 45), Tehran: Publications of Urban Planning and Architecture Research Centre, Ministry of Housing \& Urban Development of Iran. 